\title{
Laboratory test of the Dirhinus giffardii (Silvestri) (Hymenoptera: Chalcididae) against the pupae of Bactrocera cucurbitae (Coquillett) (Diptera: Tephritidae)
}

\author{
Muhammad Awais*, Niaz Hussain Khuhro, Muhammad Hamayoon \\ Khan, Raza Muhammad Memon and Muhammad Usman Asif \\ Plant Protection Division, Nuclear Institute of Agriculture (NIA), Tando jam-Pakistan \\ *Corresponding author's email: awaisrandhawa777@gmail.com \\ Citation \\ Muhammad Awais, Niaz Hussain Khuhro, Muhammad Hamayoon Khan, Raza Muhammad Memon and \\ Muhammad Usman Asif. Laboratory test of the Dirhinus giffardii (Silvestri) (Hymenoptera: Chalcididae) against \\ the pupae of Bactrocera cucurbitae (Coquillett) (Diptera: Tephritidae). Pure and Applied Biology. Vol. 9, Issue 1, \\ pp609-617. http://dx.doi.org/10.19045/bspab.2020.90066
}

\begin{tabular}{llll}
\hline \hline Received: 03/08/2019 & Revised: 25/10/2019 & Accepted: 18/11/2019 & Online First: 21/12/2019 \\
\hline \hline
\end{tabular}

\section{Abstract}

Fruit flies being serious pest of fruits and vegetables are responsible for huge economic losses in the world. Pupal parasitoid, Dirhinus giffardii is one of the most significant biological control agents that has been used effectively in controlling the fruit flies. Laboratory studies were conducted to investigate the parasitism, emergence and post emergence sex ratio of $D$. giffardii through different exposure times and parasitoid density against the pupae of melon fruit fly, Bactrocera cucurbitae. The studies manifested that the exposure time and parasitoid density had a significant effect on the parasitism and emergence ratio of parasitoids. Results revealed that mean rate of parasitism (45.66) was the highest in case of five pair of parasitoids and mean rate of emergence (42.66) of D. giffardii was also the highest on exposure period of six days. Further, it was observed that, exposure time and parasitoid density had no significant effect on the post emergence sex ratio of male and female parasitoids. The mean per female parasitism was increasing with the increase in number of pairs of $D$. giffardii and reached to its peak after exposure time of six days. These findings suggest that $D$. giffardii has a great parasitizing potential against the pupae of $B$. cucurbitae and can effectively suppress its populations.

Keywords: Bactrocera cucurbitae; Dirhinus giffardii; Emergence; Parasitism; Sex ratio

\section{Introduction}

The melon fruit fly, Bactrocera cucurbitae (Coquillett) is the most damaging pest of vegetables. It is distributed all over the world but mostly cause significant damage in Asian countries like China, Pakistan, India, New Guinea, Nepal, Hawaiian Islands and Philippines [1]. According to a survey $B$. cucurbitae harms over eighty one host plants, however it is the main pest of cucurbitaceous 
vegetables [2]. In general, the fruit flies cause massive losses to fruits and vegetables in the entire world and are known as key insect pest of the horticultural fruit plants. Approximately, they have 4,000 species which are well identified in all over the world [3]. In Pakistan, the B. cucurbitae causes 5090\% losses in fruits like melon, guava, citrus, mango and cucurbits [4]. Melon fruit fly can also injure non-cucurbit host plants by damaging their stem, flowers and root tissues [5]. The adult melon fruit fly lay 300-1000 eggs, during egg laying process ovipositor pierces the skin of fruits, after the eggs hatch, maggots begin to start feeding on the pulp of fruits by making tunnels inside the fruits [6]. During feeding, maggots consume food to store energy for the upcoming pupal stage which cause post-harvest losses and due to this reason market value of fruits become reduced [7].

In general, farmers use enormous amount of pesticides for the suppression of melon fruit fly which is declared as a quarantine pest. Agrochemicals and insecticides are notorious elements that become the prominent fragment of worldwide agriculture systems from the last century. Pesticidal leftovers did scatter in the environment, causing shocking defacement of land ecosystems and contaminating the human foods $[8,9]$. The human health is on real threat and facing certain difficult problems because in our agro-ecosystem, agrochemicals deposits are present at every time [10]. In order to control pests, growers adopt the habit of frequent and unjudicious application of pesticides as a result, insect pests develop resistance that make vulnerable their competence and also depreciate the environment [11]. Different human fitness related concerns are correlated with pesticides, such as cancers, nausea, headaches, birth defects, endocrine disruption and infertility [12]. Particularly due to constant exposure of pesticides children health is at more risk [13].
Therefore, reduce fruit fly losses by using non-chemical methods will be implemented. There are some substitutes to pesticides that do not cause the same environmental problems. One of these replacements include biological control methods which provide one of the most effective, obviously safe, and feasible mechanisms against insect pests [14]. By using biological control tactic, living organisim such as parasite, predator and disease causing organism is being introduced in to the environment of pests to reduce their population. Parasitoid, Dirhinus giffardii (Silvestri) (Hymenoptera: Chalcididae) is a useful biological control agent which can be used as a surrogate of pesticides hazards to lessening the population of fruit flies [15]. $D$. giffardii is a pupal parasitoid that attacks a wide range of fruit-infesting tephritids, including $B$. cucurbitae, $B$. tryoni, $B$. dorsalis, and B. oleae [16]. Original host of this parasitoid is Ceratitis capitate, it is native of West Africa and have the ability to parasitize dipterous houseflies $[16,17]$. It has been used for the first time in West Africa to control Black Soldier Fly [18].

Pupal parasitoid, D. giffardii pierces the puparial skin of the fruit fly pupa and oviposits inside the puparium. This parasitoid can produce healthy and bigger size offspring when its females parasitize to larger pupae of host species [19]. The fecundity rate of $D$. giffardii starts to decline as its age increases, for better mass rearing, it has been recommended that the parasitoids would be discarded after 15 days [20]. The biological control with the help of $D$. giffardii is a strong management platform of the tephretids and has quarantine importance [21]. Previous, studies were performed to determine the efficiency of $D$. giffardii on various aged pupa, but very few researches were conducted on the latent and the parasitism enactment of this parasitoid against $B$. cucurbitae. Furthermore, the present study 
was planned to evaluate the performance of D. giffardii in controlling melon fruit fly.

\section{Materials and methods}

In order to evaluate the parasitism of $D$. giffardii against pupae of $B$. cucurbitae, experiments were performed at Bio-Control Research Laboratory of Fruit Fly, Plant Protection Division, Nuclear Institute of Agriculture (NIA), Tandojam, Sindh during December, 2018. Laboratory reared culture of biological control agent D. giffardii (12 days old) and melon fruit fly pupae (2 day old) were used as a stock culture during the experiments following five replications, under laboratory conditions $\left(28 \pm 2^{\circ} \mathrm{C}\right.$ and 65 $\pm 5 \% \mathrm{RH})$. Parasitoids were released in pair form (1 pair, 2 pair, 3 pair, 4 pair and 5 pair) on each 100 pupae of melon fruit fly for different exposure periods ( 1 day, 2 day, 3 day, 4 day, 5 day \& 6 day).

\section{Rearing of Bactrocera cucurbitae}

The fruit flies, $B$. cucurbitae were mass reared on pumpkin and artificial diet containing wheat bran (26\%), sugar (12\%), dried troula yeast $(3.6 \%)$, Sodium benzoate $(0.1 \%)$, Methyl-p-hydroxybenzoate $(0.1 \%)$ and water (58\%) [22]. Eggs of fruit flies were placed directly on the diet trays having artificial diet. These eggs were collected in plastic glasses having $0.5 \mathrm{~mm}$ holes around them smeared internally with guava juice and put in adult fruit fly cages. The hatched larvae feed on the diet till complete maturation. After the full fed larvae jumped out of the trays and fell on the substrate (sand/saw dust) for pupation, the pupae were collected through sieving and used for maintaining the culture and experiments. The adult fruit flies were provided protein hydrolysate and sugar.

\section{Rearing of Dirhinus giffardii}

The colony of parasitoids $D$. giffardii being well maintained at (NIA, Tando jam) biocontrol agents rearing lab from the last several years. Parasitoids were reared in glass cages on pupae of B. cucurbitae and artificial diet, a fresh diet solution $(30 \%$ honey and
$70 \%$ water) were offered to the parasitoids through soaked cotton wigs which were impregnated with honey and water.

\section{Data analysis}

After mentioned exposure periods rate of parasitism, sex ratio and parasitoids emergence was recorded and results were analyzed by using the software statistics 8.1. One-way analysis of variance (ANOVA) and Tukey's honestly significant difference (HSD) test were used for comparisons of means among different treatments.

\section{Results}

The investigations on pupae of melon fruit fly (B. cucurbitae) were conducted by using various exposure periods and parasitoid pairs in order to check the parasitism, emergence and post emergence sex ratio of $D$. giffardii. The results obtained from the experiments showed that after the exposure time of 24 hour, the maximum mean parasitism of $24.33 \pm 1.20$ was recorded by using 5 pairs of D. giffardii followed by $17.67 \pm 1.76$, $14.67 \pm 1.20,8.33 \pm 2.03$ and $4.33 \pm 0.88$ on $4>3>2$ and 1 pair, respectively. The maximum emergence of $D$. giffardii from parasitized pupae was recorded $21.00 \pm 2.00$ while the minimum emergence was $3.33 \pm 0.88$. Analysis of variance of the present results indicated that there is a significant difference in the various treatments $(P<0.05)$. Sex ratio of emerged parasitoids showed that maximum male (59.45 \pm 3.68$)$ were recorded by 2 pairs of $D$. giffardii while maximum females $(47.57 \pm 0.25)$ were recorded after 1 day exposure period (Table 1).

After $48 \mathrm{~h}$ exposure time, results depicted that mean parasitization by 1, 2, 3, 4 and 5 pairs of D. giffardii were 7.66 \pm 1.76 , $10.33 \pm 1.46, \quad 15.00 \pm 1.73,19.33 \pm 2.02$ and $25.33 \pm 1.45$, respectively. The same sequence was also true for mean parasitoid emergence where maximum mean emergence of $D$. giffardii was $21.67 \pm 1.46$ by five pairs while the minimum emergence was recorded 
$5.00 \pm 1.15$ by 1 pair. Post emergence sex ratio of parasitoids revealed that highest male and female percentage of $D$. giffardii was $61.27 \pm 2.82$ and $49.12 \pm 0.87$, respectively. Percentage of male and female sex ratio did not differ significantly among all the treatments (Table 2). The results after 3 days exposure period showed that the maximum parasitism $(28.33 \pm 2.03)$ and maximum emergence $(26.00 \pm 1.73)$ was recorded from five pairs of $D$. giffardii. The maximum male adult emergence $(54.40 \pm 2.21)$ was observed by four pairs and maximum female adult emergence of $48.48 \pm 1.51$ was recorded from 1 pair of $D$. giffardii after the exposure time of 3 days. It was recorded that parasitoid pairs and exposure time have significant effects on the parasitism and emergence rate of $D$. giffardii. Maximum male and female sex ratio after the exposure time of four days were $54.40 \pm 2.21$ and $48.48 \pm 1.51$ by four pairs and 1 pair of $D$. giffardii, respectively (Table 3).

Results after 96 hours exposure time revealed that maximum mean parasitism was $32.33 \pm 2.61$ and minimum mean parasitism was $10.00 \pm 2.30$ by 5 and 1 pair of parasitoids, respectively. The highest rate of emergence of parasitoids was 30.33 \pm 2.90 and lowest was $8.00 \pm 2.30$ on five pairs and 1 pair of D. giffardii, respectively. Maximum post emergence sex ratio of male $D$. giffardii was $54.93 \pm 2.53$ and for female was 49.60. \pm 2.53 after the four days exposure time (Table 4). Similar trend of parasitism and emergence was observed after 120 hours exposure time, which showed that maximum mean parasitism of $35.33 \pm 4.66$ and maximum mean emergence of $33.66 \pm 4.40$ were observed by 5 pairs of $D$. giffardii. Maximum male sex ratio of emerged $D$. giffardii was $55.18 \pm 2.89$ and lowest was $48.50 \pm 0.78$ after the five days exposure time (Table 5). Results of 144 hours exposure time revealed that maximum mean parasitism and mean emergence was $45.66 \pm 2.60$ and $42.66 \pm 2.33$, respectively whereas minimum mean parasitism and mean emergence was $13.00 \pm 2.30$ and $11.33 \pm 2.60$, respectively. Lowest female percentage $(46.10 \pm 2.08)$ while the highest male percentage $(53.89 \pm 2.08)$ were recorded from single pair of D. giffardii (Table 6). Maximum per female mean parasitism by $D$. giffardii against the pupae of $B$. cucurbitae was $13.00 \pm 2.30$ and this was observed after the exposure period of $144 \mathrm{~h}$, while minimum mean per female parasitism by $D$. giffardii was $4.16 \pm 1.01$ at the exposure period of $24 \mathrm{~h}$ (Fig. 1).

Table 1. Pupae of Bactrocera cucurbitae parasitized by Dirhinus giffardii, emergence and sex ratio of parasitoids after 1 day exposure period

\begin{tabular}{|c|c|c|c|c|}
\hline No. of $\boldsymbol{D .}$ & & \multicolumn{2}{|c|}{ Sex Ratio of D. giffardii } \\
$\begin{array}{c}\text { giffardii } \\
\text { Released on } \\
\text { Host ( Pupae) }\end{array}$ & $\begin{array}{c}\text { No. of } \\
\text { Parasitized } \\
\text { Pupae }\end{array}$ & $\begin{array}{c}\text { No. of Emerged } \\
\text { D. giffardii }\end{array}$ & Male (\%) & Female (\%) \\
\cline { 4 - 5 } 1 pair & $4.33 \pm 0.88 \mathrm{c}$ & $3.33 \pm 0.88 \mathrm{~d}$ & $58.88 \pm 4.84 \mathrm{a}$ & $41.11 \pm 4.84 \mathrm{a}$ \\
\hline 2 pair & $8.33 \pm 2.03 \mathrm{c}$ & $7.00 \pm 2.31 \mathrm{~cd}$ & $59.45 \pm 3.68 \mathrm{a}$ & $40.54 \pm 3.68 \mathrm{a}$ \\
\hline 3 pair & $14.67 \pm 1.20 \mathrm{~b}$ & $11.67 \pm 1.45 \mathrm{bc}$ & $54.63 \pm 2.44 \mathrm{a}$ & $45.37 \pm 2.44 \mathrm{a}$ \\
\hline 4 pair & $17.67 \pm 1.76 \mathrm{~b}$ & $13.67 \pm 1.46 \mathrm{~b}$ & $53.89 \pm 2.08 \mathrm{a}$ & $46.10 \pm 2.08 \mathrm{a}$ \\
\hline 5 pair & $24.33 \pm 1.20 \mathrm{a}$ & $21.00 \pm 2.00 \mathrm{a}$ & $52.43 \pm 0.25 \mathrm{a}$ & $47.57 \pm 0.25 \mathrm{a}$ \\
\hline
\end{tabular}

Means sharing similar letters in columns are not significantly different at $p<0.05$ 
Table 2. Pupae of Bactrocera cucurbitae parasitized by Dirhinus giffardii, emergence and sex ratio of parasitoids after 2 days exposure period

\begin{tabular}{|c|c|c|c|c|}
\hline $\begin{array}{c}\text { No. of } \boldsymbol{D} \text {. } \\
\text { giffardii } \\
\text { Released on } \\
\text { Host ( Pupae) }\end{array}$ & $\begin{array}{c}\text { No. of } \\
\text { Parasitized } \\
\text { Pupae }\end{array}$ & $\begin{array}{c}\text { No. of Emerged } \\
\text { D. giffardii }\end{array}$ & \multicolumn{2}{|c|}{ Sex Ratio of D. giffardii } \\
\cline { 3 - 5 } & $7.66 \pm 1.76 \mathrm{~d}$ & $5.00 \pm 1.15 \mathrm{~d}$ & $61.27 \pm 2.82 \mathrm{a}$ & $38.73 \pm 2.82 \mathrm{~b}$ \\
\hline 1 pair & $10.33 \pm 1.46 \mathrm{~cd}$ & $8.33 \pm 2.02 \mathrm{~cd}$ & $53.33 \pm 3.33 \mathrm{ab}$ & $46.66 \pm 3.33 \mathrm{ab}$ \\
\hline 2 pair & $15.00 \pm 1.73 \mathrm{bc}$ & $13.33 \pm 1.45 \mathrm{bc}$ & $52.79 \pm 1.41 \mathrm{ab}$ & $47.20 \pm 1.41 \mathrm{ab}$ \\
\hline 3 pair & $19.33 \pm 2.02 \mathrm{ab}$ & $17.00 \pm 1.73 \mathrm{ab}$ & $57.70 \pm 4.16 \mathrm{ab}$ & $42.29 \pm 4.16 \mathrm{ab}$ \\
\hline 4 pair & $25.33 \pm 1.45 \mathrm{a}$ & $21.67 \pm 1.46 \mathrm{a}$ & $50.87 \pm 0.87 \mathrm{~b}$ & $49.12 \pm 0.87 \mathrm{a}$ \\
\hline 5 pair & &
\end{tabular}

Means sharing similar letters in columns are not significantly different at $p<0.05$

Table 3. Pupae of Bactrocera cucurbitae parasitized by Dirhinus giffardii, emergence and sex ratio of parasitoids after 3 days exposure period

\begin{tabular}{|c|c|c|c|c|}
\hline \multirow{2}{*}{$\begin{array}{c}\text { No. of } D . \\
\text { giffardii } \\
\text { Released on } \\
\text { Host ( Pupae) }\end{array}$} & \multirow{2}{*}{$\begin{array}{c}\text { No. of } \\
\text { Parasitized } \\
\text { Pupae }\end{array}$} & \multirow{2}{*}{$\begin{array}{c}\text { No. of Emerged } \\
\text { D. giffardii }\end{array}$} & \multicolumn{2}{|c|}{ Sex Ratio of $D$. giffardii } \\
\hline & & & Male (\%) & Female $(\%)$ \\
\hline 1 pair & $8.33 \pm 2.02 \mathrm{~d}$ & $7.00 \pm 2.08 \mathrm{~d}$ & $51.51 \pm 1.51 \mathrm{a}$ & $48.48 \pm 1.51 \mathrm{a}$ \\
\hline 2 pair & $13.00 \pm 2.30 \mathrm{~cd}$ & $11.33 \pm 2.60 \mathrm{~cd}$ & $53.89 \pm 2.08 \mathrm{a}$ & $46.10 \pm 2.08 \mathrm{a}$ \\
\hline 3 pair & $18.00 \pm 2.30 \mathrm{bc}$ & $16.00 \pm 2.30 \mathrm{bc}$ & $51.66 \pm 1.66 \mathrm{a}$ & $48.33 \pm 1.66 \mathrm{a}$ \\
\hline 4 pair & $23.00 \pm 2.31 \mathrm{ab}$ & $21.00 \pm 2.31 \mathrm{ab}$ & $54.40 \pm 2.21 \mathrm{a}$ & $45.59 \pm 2.21 \mathrm{a}$ \\
\hline 5 pair & $28.33 \pm 2.03 \mathrm{a}$ & $26.00 \pm 1.73 \mathrm{a}$ & $52.74 \pm 1.95 \mathrm{a}$ & $47.25 \pm 1.95 \mathrm{a}$ \\
\hline
\end{tabular}

Means sharing similar letters in columns are not significantly different at $p<0.05$

Table 4. Pupae of Bactrocera cucurbitae parasitized by Dirhinus giffardii, emergence and sex ratio of parasitoids after 4 days exposure period

\begin{tabular}{|c|c|c|c|c|}
\hline No. of $\boldsymbol{D .}$ & & \multicolumn{2}{|c|}{ Sex Ratio of D. giffardii } \\
$\begin{array}{c}\text { giffardii } \\
\text { Released on } \\
\text { Host ( Pupae) }\end{array}$ & $\begin{array}{c}\text { No. of } \\
\text { Parasitized } \\
\text { Pupae }\end{array}$ & $\begin{array}{c}\text { No. of Emerged } \\
\text { D. giffardii }\end{array}$ & Male (\%) & Female (\%) \\
\cline { 4 - 5 } 1 pair & $10.00 \pm 2.30 \mathrm{~d}$ & $8.00 \pm 2.30 \mathrm{~d}$ & $52.00 \pm 1.41 \mathrm{a}$ & $48.00 \pm 1.41 \mathrm{a}$ \\
\hline 2 pair & $15.00 \pm 2.30 \mathrm{~cd}$ & $13.33 \pm 2.02 \mathrm{~cd}$ & $54.22 \pm 2.55 \mathrm{a}$ & $45.77 \pm 2.55 \mathrm{a}$ \\
\hline 3 pair & $21.00 \pm 2.31 \mathrm{bc}$ & $19.00 \pm 2.30 \mathrm{bc}$ & $54.93 \pm 2.53 \mathrm{a}$ & $45.06 \pm 2.53 \mathrm{a}$ \\
\hline 4 pair & $26.33 \pm 2.60 \mathrm{ab}$ & $24.33 \pm 2.02 \mathrm{ab}$ & $50.39 \pm 1.72 \mathrm{a}$ & $49.60 \pm 2.53 \mathrm{a}$ \\
\hline 5 pair & $32.33 \pm 2.61 \mathrm{a}$ & $30.33 \pm 2.90 \mathrm{a}$ & $51.68 \pm 0.168 \mathrm{a}$ & $48.32 \pm 0.16 \mathrm{a}$ \\
\hline
\end{tabular}

Means sharing similar letters in columns are not significantly different at $p<0.05$ 
Table 5. Pupae of Bactrocera cucurbitae parasitized by Dirhinus giffardii, emergence and their sex ratio of parasitoids after 5 days exposure period

\begin{tabular}{|c|c|c|c|c|}
\hline No. of $\boldsymbol{D}$. & giffardii \\
Released on & No. of & Parasitized \\
Host ( Pupae) & Pupae & $\begin{array}{c}\text { No. of Emerged } \\
\text { D. giffardii }\end{array}$ & Male (\%) & Female (\%) \\
\cline { 4 - 5 } 1 pair & $11.00 \pm 2.30 \mathrm{c}$ & $9.33 \pm 2.60 \mathrm{c}$ & $55.18 \pm 2.89 \mathrm{a}$ & $44.81 \pm 2.89 \mathrm{~b}$ \\
\hline 2 pair & $18.33 \pm 2.60 \mathrm{bc}$ & $16.66 \pm 2.33 \mathrm{bc}$ & $52.07 \pm 1.120 \mathrm{ab}$ & $47.92 \pm 1.12 \mathrm{ab}$ \\
\hline 3 pair & $26.33 \pm 2.60 \mathrm{ab}$ & $24.00 \pm 2.30 \mathrm{ab}$ & $54.00 \pm 2.52 \mathrm{~b}$ & $46.00 \pm 2.49 \mathrm{~b}$ \\
\hline 4 pair & $34.66 \pm 3.17 \mathrm{a}$ & $32.00 \pm 3.17 \mathrm{a}$ & $51.49 \pm 0.78 \mathrm{ab}$ & $48.50 \pm 0.78 \mathrm{a}$ \\
\hline 5 pair & $35.33 \pm 4.66 \mathrm{a}$ & $33.66 \pm 4.40 \mathrm{a}$ & $52.22 \pm 0.81 \mathrm{ab}$ & $47.77 \pm 0.81 \mathrm{ab}$ \\
\hline
\end{tabular}

Means sharing similar letters in columns are not significantly different at $p<0.05$

Table 6. Pupae of Bactrocera cucurbitae parasitized by Dirhinus giffardii, emergence and sex ratio of parasitoids after 6 days exposure period

\begin{tabular}{|c|c|c|c|c|}
\hline No. of $\boldsymbol{D .}$ & & \multicolumn{2}{|c|}{ Sex Ratio of D. giffardii } \\
$\begin{array}{c}\text { giffardii } \\
\text { Released on } \\
\text { Host ( Pupae) }\end{array}$ & $\begin{array}{c}\text { No. of } \\
\text { Parasitized } \\
\text { Pupae }\end{array}$ & $\begin{array}{c}\text { No. of Emerged } \\
\text { D. giffardii }\end{array}$ & Male (\%) & Female (\%) \\
\cline { 4 - 5 } 1 pair & $13.00 \pm 2.30 \mathrm{~d}$ & $11.33 \pm 2.60 \mathrm{~d}$ & $53.89 \pm 2.08 \mathrm{a}$ & $46.10 \pm 2.08 \mathrm{a}$ \\
\hline 2 pair & $22.00 \pm 2.30 \mathrm{c}$ & $19.33 \pm 2.40 \mathrm{c}$ & $51.38 \pm 1.38 \mathrm{a}$ & $48.61 \pm 1.38 \mathrm{a}$ \\
\hline 3 pair & $27.66 \pm 2.90 \mathrm{bc}$ & $24.66 \pm 2.90 \mathrm{bc}$ & $52.77 \pm 1.46 \mathrm{a}$ & $47.22 \pm 1.46 \mathrm{a}$ \\
\hline 4 pair & $35.00 \pm 2.30 \mathrm{~b}$ & $31.66 \pm 2.33 \mathrm{~b}$ & $51.72 \pm 1.03 \mathrm{a}$ & $48.27 \pm 1.03 \mathrm{a}$ \\
\hline 5 pair & $45.66 \pm 2.60 \mathrm{a}$ & $42.66 \pm 2.33 \mathrm{a}$ & $51.57 \pm 0.40 \mathrm{a}$ & $48.42 \pm 0.40 \mathrm{a}$ \\
\hline
\end{tabular}

Means sharing similar letters in columns are not significantly different at $p<0.05$

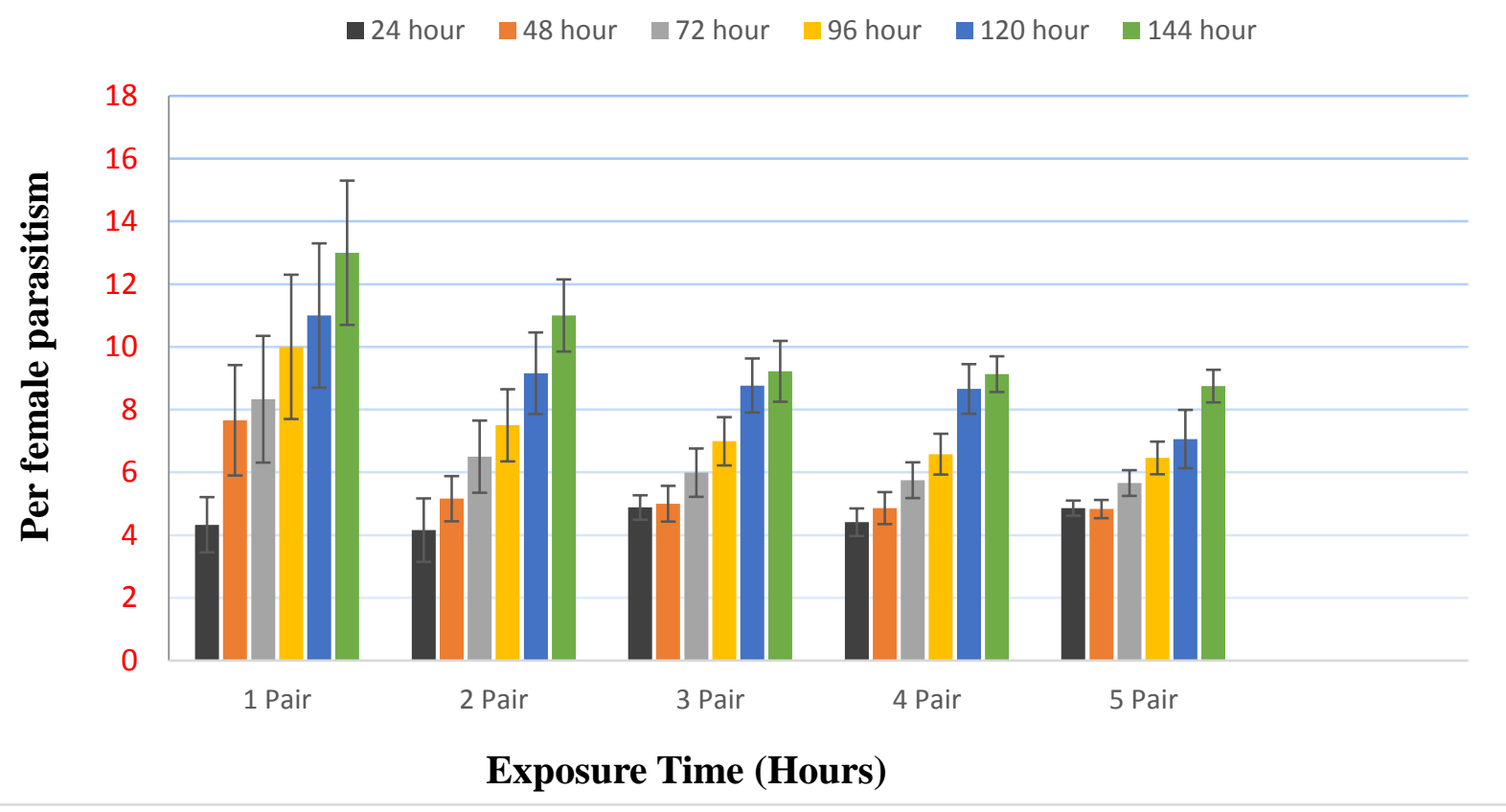

Figure 1. The per female parasitism rate of Dirhinus giffardii against the pupae of Bactrocera cucurbitae on different exposure periods $(\mathrm{P} \leq \mathbf{0 . 0 5})$ 


\section{Discussion}

The parasitism, emergence and post emergence sex ratio of $D$. giffardii through different exposure times and parasitoid pairs were tested using laboratory experiments. A pronounced effect of parasitoids and exposure time on parasitism rate of $D$. giffardii was noticed. Results showed that number of parasitoids and exposure time have significant effects on the parasitism rate of D. giffardii against pupae of melon fruit fly. Maximum mean parasitization was observed at the $144 \mathrm{~h}$ exposure time and lowest at the $24 \mathrm{~h}$. The present study confirmed that the pupal parasitoid $D$. giffardii is highly effective to parasitize the melon fruit fly pupae [21]. The trend of parasitization showed that increasing parasitoid pairs have significant effects on the rate of parasitism. It was observed that, as the number of parasitoid pairs on the pupae of melon fruit fly increased, meanwhile rate of parasitized pupae also increased, due to increase in per female parasitization and exposure time. Results showed that pupal parasitoid $D$. giffardii have high level of parasitism against the pupae of $B$. cucurbitae. Biological control by using D. giffardii could be an effective and safe approach for controlling tephritid flies. The method was successful and worth applying in the control of these pests [23-26].

The relationship between parasitization and emergence ratio of parasitoids strongly supports the phenomena that as we increase the parasitoid pairs, the number of emerged parasitoids also increase. It was observed that maximum mean emergence was in case of five pair of parasitoids while exposure time also had significant effect on the emergence of D. giffardii. Results revealed that based on exposure periods, the rate of mean parasitoid emergence trend was observed in following order 6 day $>5$ day $>4$ day $>3$ day $>2$ day $>$ and 1 day, respectively.
The trend of post emergence sex ratio depicted that male and female emerged parasitoids were not in equal numbers and exposure time and number of parasitoids have no significant effect on them. Some factors are known to influence the sex ratio of parasitoid progeny, such as parental sex ratio, host size, and host age, while parasitoids (Itoplectis naranyae and Pimpla nipponica) could change the sex ratio of their offspring in response to host age [27-29]. In contrast [30] reported that the age of the host had no effect on the progeny sex ratio of the wasp Brachymeria lasus. In our study, we found that the male and female emerged parasitoids were almost in different proportion but in some observations males were dominant regarding sex ratio [31]. Further, it was concluded that number of parasitoids, exposure time and per female parasitism significantly interlinked with each other (Fig. 1).

\section{Conclusion}

In conclusion, parasitism rate and emergence percentage of the pupal parasitoid, $D$. giffardii was satisfactory on the host (Melon fruit fly pupae). The results suggest that $D$. giffardii could be a suitable candidate for the biological control of $B$. cucurbitae. The present study will also be helpful in reduction of the fruit flies population through mass production and release of pupal parasitoid $D$. giffardii.

\section{Authors' contributions}

Conceived and designed the experiments: $\mathrm{M}$ Awais \& NH Khuhro, Performed the experiments: M Awais, MH Khan \& MU Asif, Analyzed the data: M Awais \& RM Memon, Contributed reagents/ materials/ analysis tools: $\mathrm{M}$ Awais, $\mathrm{MH}$ Khan, RM Memon \& MU Asif, Wrote the paper: M Awais \& NH Khuhro.

\section{References}

1. Weems HV \& Heppner JB (2001). Melon fly, Bactrocera cucurbitae (Coquillett) (Diptera: Tephritidae). 
Florida Department of Agriculture and Consumer Services, Division of Plant Industry, Uni Flor Pub EENY-199.

2. Dhillon MK, Singh R, Naresh JS \& Sharma HC (2005). The melon fruit fly, Bactrocera cucurbitae: A review of its biology and management. J Insect Sci 5(1): 1-16.

3. Hardy DE (1997). Taxonomy and distribution of the oriental fruit fly and related species (Tephritidae: Diptera). Proc. Hawai. Entomol. Society, 20: 395428.

4. Sajjad M, Hafiz M, Muhammad N \& Muhammad T (2017). Fruit Fly: A Serious Insect Pest of Horticultural Crops in Pakistan. Internet: https://www.technologytimes.pk/?p=17 197

5. OKE OA (2008). Effectiveness of two insecticides to control melon fruit fly (Bactrocera cucurbitae) in cucumber (Cucumis sativus L) crop at Anse Boileau Seychelles. Eur J Sci Res 22(1): 84-86.

6. Jackson CG, Vargas RI \& Suda DY (2003). Populations of Bactrocera cucurbitae (Diptera: Tephritidae) and its parasitoid, Psyttalia fletcheri (Hymenoptera: Braconidae) in Coccinia grandis (Cucurbitaceae) or ivy gourd on the island of Hawaii. Proc. Hawai. Entomol. Soci., 36: 39-46.

7. Latif A (2004). Integrated management of Fruit flies (Diptera: Tephritidae) in Pakistan. Annual Report of Agricultural Linkages Programme. Pak. Agri. Res. Coun (Islamabad):1-51.

8. Carson R (1962). The silent Spring. Houghton Mifflin, New York.

9. EEA (2013). Late lessons from early warnings: science precaution, innovation. European Environment Agency, Report No 1/2013. EEA, Copenhagen.
10. Jeyaratnam J (1990). Acute pesticide poisoning: A major global health problem. World Health Stat Q (43): 139144.

11. Van Emden HF \& Service MW (2004). Book on pest and vector control. Cambridge, UK: Cambridge University Press.

http://dx.doi.org/10.17/CBO978051161 6334.

12. Alavanja MCR, Ross MK \& Bonner MR (2013) Increased cancer burden among pesticide applicators and others due to pesticide exposure. Cancer J Clin (63): 120-142.

13. Lozowicka B (2015). Health risk for children and adults consuming apples with pesticide residue. Sci. Total Environ (502): 184-198.

14. Mian LGN, Marwat A, Latif and Shah GS (1986). Testing and evaluation of various pesticides and cultivars on muskmelon against melon fruitfly Dacus cucurbitae Coq. (Diptera: Tephritidae) in D.I. Khan. Sarhad J Agric 2(2): 403410.

15. Van DR, Hoddle M \& Center T (2008). Book on Control of Pests and Weeds by Natural Enemies, Hoboken, NJ, USA: Wiley-Blackwell.

16. Wharton RA \& Yoder MJ (2018). Parasitoids of Fruit-Infesting Tephritidae. Internet: http://paroffit.org

17. Mohamed SA, Wharton RA, Von Merey G \& Schulthess F (2006). Acceptance and suitability of different host stages of Ceratitis capitata (Wiedemann) (Diptera: Tephritidae) and seven other tephritid fruit fly species to Tetrastichus giffardii SILVESTRI (Hymenoptera: Eulophidae). Biol Control 39(3): 262271.

18. Device E \& Maquart PO (2015). Dirhinus giffardii (Hymenoptera: Chalcididae), parasitoid affecting Black 
Soldier Fly production systems in West Africa. Entomologia 3(284): 25-27.

19. Wang XG \& Messing RH (2004a). Two different life-history strategies determine the competitive outcome between Dirhinus giffardii (Chalcididae) and Pachycrepoideus vindemmiae (Pteromalidae), ectoparasitoids of cyclorrhaphous Diptera. Bull Entomol Res 94(5): 473-480.

20. Shah SMM, Ahmad N, Sarwar M \& Tofique M (2014). Rearing of Bactrocera zonata (Diptera: Tephritidae) for parasitoids production and managing techniques for fruit flies in mango orchards. Int J Trop Insect Sci 34(S1): S108-S113.

21. Wang XG \& Messing RH (2004b). The ectoparasitic pupal parasitoid, Pachycrepoideus vindemmiae (Hymenoptera: Pteromalidae), attacks other primary Tephritid fruit fly parasitoids: host expansion and potential non-target impact. Biol Cont 31: 227236.

22. Khan $\mathrm{MH}$, Khuhro $\mathrm{NH}$, Awais $\mathrm{M}$, Memon RM and Akbar W (2019). Assessment of the parasitism potential of three parasitoids of fruit fly, Bactrocera spp. (Diptera: Tephritidae) under laboratory conditions. Pure Appl Biol 8(2): 1579-1587.

23. Purcell MF (1998). Contribution of biological control to integrated pest management of tephritid fruit flies in the tropics and subtropics. Integ Pest Manag $\operatorname{Rev} 3(2)$ : 63-83.

24. Vargas RI, Leblanc L, PUTOA R, Eitam A (2007). Impact of introduction of Bactrocera dorsalis (Diptera: Tephritidae) and classical biological control releases of Fopius arisanus (Hymenoptera: Braconidae) on economically important fruit flies in French Polynesia. $J$ Econ Entomol 100(3): 670-679.

25. Zamek AL, Spinner JE, Micallef JL, Gurr GM, Reynolds OL (2012). Parasitoids of Queensland fruit fly Bactrocera tryoni in Australia and prospects for improved biological control. Insects 3(4): 1056-1083.

26. Tang LD, JI XC, Han Y, Fub L, Liu K (2015). Parasitism, emergence, and development of Spalangia endius (Hymenoptera: Pteromalidae) in pupae of different ages of Bactrocera cucurbitae (Diptera: Tephritidae). J Insect Sci 15(1): 15.

27. Mohamed M \& Coppel H (1986). Sex ratio regulation in Brachymeria intermedia, a pupal gypsy moth parasitoid. Can J Zool 64: 1412-1415.

28. Barbosa P \& Frongillo E (1979). Host parasitoid interactions affecting reproduction and oviposition by Brachymeria intermedia (Hymenoptera: Chalcididae). Bio Control 24: 139-143.

29. Ueno T (1999). Host size dependent sex ratio in a parasitoid wasp. Res Popul Ecol 41: 47-57.

30. Husni Y, Kainoh \& Honda H (2001). Effects of host pupal age on host preference and host suitability in Brachymeria lasus (Walker) (Hymenoptera: Chalcididae). Appl Entomol Zool 36: 97-102.

31. Awais M, Khuhro NH, Khan MH, Memon RM and Asif MU (2018). Assessment of parasitizing potential of pupal parasitoid Dirhinus giffardii (Silvestri) against different age pupae of fruit fly and their post emergence sex ratio under lab conditions. $J$ Entomol Zool Studies 6(5): 159-162. 